\title{
Considerations on the Curation of Educational Apps for Digital Play and Learning
}

\author{
Fei Victor Lim ${ }^{{ }^{*}}$ \\ (iD) 0000-0003-3046-1011 \\ Weimin Toh ${ }^{1}$ \\ (D) 0000-0002-6468-227X \\ ${ }^{1}$ National Institute of Education, Nanyang Technology University, SINGAPORE
${ }^{*}$ Corresponding author: Victor.lim@nie.edu.sg
}

Citation: Lim, F. V., \& Toh, W. (2022). Considerations on the Curation of Educational Apps for Digital Play and Learning. Contemporary Educational Technology, 14(3), ep366. https://doi.org/10.30935/cedtech/11809

\section{ARTICLE INFO}

Received: 4 Jan 2022

Published: 12 Feb 2022

\begin{abstract}
Mobile devices have become increasingly ubiquitous in the contemporary communication landscape. Riding this trend, educational apps have proliferated the market, with many which claim to support and improve children's learning and literacy development. Caregivers are often faced with the challenge of discerning the value of these educational apps and in choosing the appropriate apps for their children. In this paper, we discuss the development of a set of considerations to support caregivers in their curation of educational apps. This is done by performing a review of 28 past studies done on educational apps and synthesizing their findings to draw out common themes from the literature. These themes are then categorized into nine considerations in the form of guiding questions that caregivers can use to curate educational apps for their children's digital play and learning. In the final part of our paper, we apply the set of considerations to three educational apps to demonstrate its utility.
\end{abstract}

Keywords: curation, digital learning, digital play, educational apps

\section{INTRODUCTION}

The advancements in digital technology and the affordability of mobile devices have made digital play an increasingly common phenomenon amongst children (Djonov et al., 2021; Hatzigianni et al., 2018; Lim \& Toh, 2020; Toh \& Lim, 2022). Many children, even from a young age, have access to a mobile device and are exposed to the use of various apps. Riding this trend, companies have produced educational apps, many of which claim to support and improve children's learning and literacy development. As an increasing number of educational apps flood the market, we posit that it is useful to have a set of considerations that can support caregivers, such as parents and teachers, in their curation of educational apps which can be used for their children's literacy development.

Noorhidawati et al. (2015) found that children learn through their experience when interacting with the educational apps in their learning incidents related to knowledge (cognitive); actions/motor skills (psychomotor); and attitudes, feelings, and emotions (affective). Research have also provided empirical support for the use of educational apps in addressing early achievement gaps (e.g., Griffith et al., 2019) and supporting early learning (e.g., Arnold et al., 2021; Dore et al., 2019; Griffith et al., 2020). Kolak et al. (2021) reviewed eight tools that have been developed in recent studies (2015-2000) to assess the educational potential and design of apps for children (Callaghan \& Reich, 2018; Department for Education, 2019; HirshPasek et al., 2015; Lee \& Kim, 2015; Lee \& Sloan Cherner, 2015; Papadakis et al., 2018; Papadakis \& Kalogiannakis, 2017; Shoukry et al., 2015). They found that only three out of eight tools were aimed at caregivers and almost all of the tools have a long list of criteria which makes it time consuming and impractical for caregivers to curate educational apps. Hirsh-Pasek et al. (2015) explicated that educational apps must be 
designed to promote four psychological principles, namely, active, engaged, meaningful, and socially interactive learning within the context of a supported learning goal. Likewise, de Aguiar et al. (2018) proposed a model for educational digital games that is informed by learning theories and responsive to the user experience. More specifically for literacy development, and following our earlier work in developing frameworks for video games in learning (Toh \& Kirschner, 2020; Toh \& Lim, 2021b), we also developed a framework to describe the rich meaning potential of educational apps for language learning and explicate the choices players have in their engagement and play in the app (Toh \& Lim, 2022). In this paper, we draw from the findings and work from de Aguiar et al., (2018), Hirsh-Pasek et al. (2015), Lim (2018), Lim et al. (2022), Lim and Tan (2017), Noorhidawati et al. (2015), and others to develop a set of considerations to support the caregivers in their curation of educational apps.

In this paper, we build on the work of Dubé et al. (2020) and Kolak et al. (2021) on the importance of helping parents and educators identify quality educational apps. We echo their concern regarding the present lack of transparency and meaningful information to support caregivers in their curation of educational apps. To address this challenge, we propose the development of a set of considerations for caregivers that can guide them in their curation of educational apps for young children. We conduct a review of relevant literature and identify the principles highlighted from these studies. The ideas are organized according to categories and expressed as specific considerations for the caregivers to apply in their curation of educational apps. We then illustrate how the set of considerations can be used in the curation of three educational apps - The Big Brag app, the Super Why Alpha Boost! app, and the Angry Birds app. Our paper is guided by the research question: What are the considerations, based on past studies, for caregivers to curate educational apps?

\section{METHODOLOGY}

This paper is theoretically-oriented in that it builds on past research on educational apps, digital play and learning to develop a set of considerations for caregivers in their curation of apps for learning. Keyword search was carried out using the following terms: "educational apps and learning", "mobile apps and learning", "designing learning with educational apps", "educational apps and user experience", "game design and learning", "evidence-based app development", and "multimodality and learning with digital apps".

The following online databases were searched: NIE (National Institute of Education) libris, Google Scholar, Science Direct, and EBSCO library resource. We included publications from journals such as Psychological Science in the Public Interest, Reading Research Quarterly, Reading Psychology, British Journal of Educational Technology, TESOL Quarterly, Intervention in School and Clinic, Journal of Child-Computer Interaction, Frontiers in Psychology, and others.

During the synthesis of the findings from prior research, a thematic analysis using the methodology of grounded theory (Kiger \& Varpio, 2020; Lochmiller, 2021; Nowell et al., 2017; Tuckett, 2005; Xu \& Zammit, 2020) was applied to draw out common themes from the literature and then categorized to develop the set of considerations. For example, a focus on emotions was reported to be important in helping children express their ideas about the world based on studies conducted by Hirsh-Pasek et al. (2015) and Noorhidawati et al. (2015). Affective learning is about engaging with the children's emotion, attitude, and values when interacting with the apps. For instance, the app may represent characters' emotions using both language and visual resources for children to develop social awareness. When the caregiver understands how language (e.g., use of the word happy) is related to the visuals of the characters' emotions (e.g., a smiling face) in the story, they may be able to curate the apps for teaching children to identify emotions because the app uses a contextualized approach for the learning activities.

\section{CONSIDERATIONS FOR EDUCATIONAL APPS}

Based on the themes identified, we develop a set of considerations for the curation of educational apps below. We present these considerations in light of the relevant research and provide examples of educational apps that illustrate the principles. 


\section{Learning: What Learning Does the App Offer?}

Our first consideration focuses on the learning from the child's use of the educational app. Studies have reported that specific educational apps can support children in learning vocabulary that is achieved through image-sound-letters association (Cassady \& Smith, 2005), in developing reading fluency and non-word spelling (Ponce et al., 2012), and in improving reading comprehension (Kim et al., 2011; Schneider et al., 2016). Apps can also help children develop multimodal literacy (Kress \& Jewitt, 2003; Lim, 2021; Towndrow et al., 2013; van Leeuwen, 2017) when they communicate meaning by combining different modes such as animation, speech, images, colors, and music, to support vocabulary teaching and learning (Vungthong et al., 2015).

Educational apps can also develop children's socio-emotional skills (CASEL, 2019; Lim et al., 2021; Toh \& Lim, 2022; Withey, 2016). We define social-emotional learning in terms of children's learning of self-awareness (i.e., recognizing one's emotions and thoughts and their influence on behaviors), social awareness (i.e., perspective taking), self-management (i.e., self-regulation), relationship skills, and responsible decisionmaking (CASEL, 2019; Selander et al., 2018; Toh, 2021). The app may introduce general emotion regulation and teach children ways to manage their emotions. For example, they can encourage children to calm down using visual cues and count backwards from ten, accompanied by a deep breathing prompt. Apps may also use stories to assure children that it is normal for them to experience strong emotions from time to time. Some educational apps also provide opportunities to build children's emotional awareness. For example, Lim, et al. (2021) describes Collin's World as a scenario-based game where the players experience an ethical dilemma and navigate the choices offered.

Educational apps can also be used to develop children's creativity (Kucirkova \& Sakr, 2015). For example, the Coloring Games app may have the child create art using everyday objects and offer options for them to share their completed product on an online gallery or on social media with their family or friends. Digital play can also help develop children's problem-solving skills (Tarasuik et al., 2017; Toh \& Lim, 2021a). For example, the child may be given a problem-solving task in the Tami's Tower app to solve together with a caregiver.

\section{Learning Design: How Does the Learning Take Place?}

The second consideration is to identify the way learning is designed for in the educational app. The caregivers can reflect on whether the learning is by practice (transmissionist), by reinforcement (behaviorist), or with others (social constructivist), and decide if the approach is appropriate for their child.

Learning by practice involves the repeated verbal or written performance such as repetitively tracing a Chinese ideograph. Despite the repetitive requirement of rote learning tasks, there is the possibility that automatic and spontaneous encodings will still occur (Pressley \& Levin, 1985). Rote learning is less effective when it does not connect to previously learned content in any substantial way (Ausubel, 1968). However, it can serve as a precursor to 'real learning' when implicit knowledge can be activated.

Learning by reinforcement uses rewards (e.g., immediate positive feedback and hidden objects in apps) to motivate the child. Through strengthening stimulus-response associations in the environment, the learners' performance improves (Smith \& Ragan, 2005). Examples of learning by reinforcement in educational apps include a focus on the learners' recall of facts (using quizzes), illustration of concepts, application of explanations, and the following of procedures.

Learning with others focuses on the social construction of knowledge (Wise \& Jacobo, 2010). Knowledge is co-constructed with the caregiver through talk (Hindman et al., 2014; Parish-Morris et al., 2013) and the social interaction (Nightingale \& Cromby, 1999). Some apps are designed to create opportunities for learning with others. An example is the Peppa Pig Me books app that has a feature which allows children to record their own dialogue page, which allows for play and review with the caregivers.

\section{Values: What are the Ideas Promoted?}

The third consideration for caregivers is to recognize the values promoted in the educational apps. Caregivers should consider the intended and incidental lessons promoted in the app to their child. For instance, in Dr Seuss' The Cat in the Hat, the Cat urges the children to be responsible for their behavior by cleaning up their own mess or take responsibility for the consequence of their behavior. Towards the end of the story, the Cat demonstrates the positive behavior of discipline and responsibility by cleaning up the mess 
it has created and encourages children to model its behavior. In this, the app is transmitting specific values that socialize the child to certain norms.

Narrative representations in educational apps may also portray gender in a stereotypical and noninclusive manner. For instance, the female gender may be depicted in more nurturing roles such as in nursing occupations, playing a domestic role in homes or serving as preschool educators, hence perpetuating certain gender normativity. Children tend to internalize gendered notions of societal roles and expectations when they are exposed to these stereotypes from a young age (Lin et al., 2017). As such, it is important for the caregivers to consider the ideas promoted in the educational app to their child.

\section{Interactivity: Does It Encourage Active Interaction Rather Than Passive Viewing?}

The fourth consideration for caregivers is the level of interactivity which the app offers. Such features promote embodied learning where children can actively participate (Papert, 1995) and exercise their agency (Squires \& Preece, 1999) in their interaction with the educational app. Embodied learning provides grounding for language and thought (Gibbs, 2003, 2005). Educational apps can have features that encourage children to exert physical and cognitive effort in learning. For example, a mathematics app that is designed to build children's skills at understanding quantity may present analogue representations of physical objects while supporting direct manipulation of the virtual objects with multimodal feedback such as verbal labelling of quantities ('You caught 5 fireflies!'), visuals (fireflies' representations), and numerical representations ('5') (Hirsh-Pasek et al., 2015). Another example is Nosy Crow's The Three Little Pigs. Children may take on the perspective of characters such as the big bad wolf and blow into the microphone to simulate his action of blowing at the pigs' newly constructed houses (to learn the word 'blow') or they can tap on hidden objects in the surroundings of the story world to enhance their story experience.

Notwithstanding, caregivers should also be mindful of the potential negative effects of the inclusion of interactive hotspots in educational apps. Piotrowski and Krcmar (2017) reported that children paid greater attention to the story content when there were less interactive features. They argued that the haptic use encouraged by the interactive features was distracting to the reading task. Bus et al. (2015) also suggested that the presence of games and interactive features incidental to the storyline, reduce the children's language comprehension. Likewise, in their meta-analysis of the effects of technology-enhanced stories for young children's literacy development, Takacs et al. (2015) reported that the positive effects of educational apps fade when they contain interactive elements such as games and interactive features due to cognitive overload. As such, it is useful for caregivers to reflect on the nature of interactivity offered by the specific app, and ascertain the sweet spot between engagement and distraction.

\section{Involvement: Does It Encourage Co-Play with Others?}

The fifth consideration is whether the app supports interactions with others during and after its use. Interaction (Hirsh-Pasek et al., 2015) and guided play (Dickinson et al., 2013; Nicolopoulou et al., 2018; Toh \& Lim, 2021a) can enhance children's learning. A good educational app facilitates co-learning with caregivers and co-play with other peers. For example, apps with animation or animated features could engage the child's attention (Sung \& Chen, 2018) and facilitate verbal interactions with the caregiver through questions or comments (Barnes et al., 2016) such as labelling or describing (Barnes, 2013) to explore the deeper meaning behind the words or concepts.

Educational apps could also support caregiver-child interaction by including distancing prompts (ParishMorris et al., 2013; Reese \& Cox, 1999) or scaffolding questions (Blewitt et al., 2009) to develop the child's vocabulary. One example is, Journey, a game developed by Thatgamecompany, that provides a multiplayer option for players to cooperate to progress their journey in the game. It involves puzzle-solving that creates an opportunity for children to co-play with peers and facilitate co-learning with caregivers to solve the puzzles to enable their progress.

\section{Motivation: Does It Motivate Learning Beyond the App?}

The sixth consideration is the extent in which the app motivates further learning. Some educational apps use gamified elements to encourage the child's learning (Kezar \& Rhoads, 2001; Kuh, 1996). Gamified elements include features that are commonly found in games such as gameplay mechanics, a reward (point 
based) system, problem solving environments, clear goals, challenges, and others that are used in non-game applications including educational apps to motivate learning (Deterding et al., 2011; Dichev \& Dicheva, 2017). Gamified elements can foster extrinsic motivation in children to encourage use of the app and learning beyond the app through feedback (Brown, 1994). The extrinsic motivation can develop into intrinsic motivation (Malone \& Lepper, 1987) when the child experiences both feelings of competence and autonomy (Mekler et al., 2017) as well as develops interest in specific areas. An example is The Cat in the Hat Builds that app. It includes three games introducing science and engineering concepts for preschoolers. When caregivers or children tap on the book in the tree house, they can find off-screen STEM extensions and activities to continue their learning beyond the app. The integration of augmented reality (AR) technology in educational apps may also motivate children (Juan et al., 2008; Liu et al., 2009), foster knowledge retention (Perez-Lopez \& Contero, 2013), and inspire their curiosity to learn beyond the app (Morrison et al., 2009). For example, Aug That uses the camera feature of mobile devices to trigger 3-dimensional shapes for children's learning and interactions beyond the app.

\section{Ease of Use: Is It Intuitive to Use?}

The seventh consideration is in terms of how easy it is for the child to navigate and use the app independently. When evaluating the app's ease of use, caregivers can consider whether the app is appropriately designed according to the child's level of knowledge of technology use. The principles of simplicity and intuitive design are important because they directly affect the user experience and satisfaction when using the app (Eyal \& Hoover, 2014). An intuitive user interface reduces the effort needed to use the app (Pelton \& Pelton, 2011). Zhao and Unsworth (2017) argue that an educational app scaffolds the child's learning of how to interact with it by building on the user's current knowledge of how they interact with print texts. For example, the user interface of Dr. Seuss' The Cat in the Hat app may simulate how we interact with books by swiping the screen to mimic the turning of the pages in a book.

\section{Appropriateness: Is It (St)age Appropriate for the Child?}

The eighth consideration is the appropriateness of the educational app to the child's developmental stage. Research has shown that educational apps that provide developmentally appropriate content help children build a foundational understanding of basic concepts before engaging with more sophisticated and complex material (Callaghan \& Reich, 2018). Some apps support children's learning through personalization (Kucirkova, 2019) to the knowledge level and (st)age appropriateness of children based on feedback from children's actions (Chew \& Mitchell, 2019). For example, in the Preschool and Kindergarten Learning Kids Games app, the child can learn to recognize the shape of the letter through the action of tracing its outline at the foundational level. Children can start with easy tracing at first and then move gradually to tracing requiring more developed fine-motor skills. After learning word recognition and writing, the child can proceed to learn the meanings of words (Brown et al., 2014; Hadley et al., 2018) in the reading comprehension level.

Caregivers could also reflect on the language level used in the app and the difficulty level of the educational app's content offered to the child prior to the child's use of it by reading the app's description on the website and watching how the app functions on YouTube. They may also try a demonstration version of the app that can be downloaded on the website prior to purchase.

\section{Appeal: Is It Attractive to the Child?}

The final consideration is the aesthetics of the app and how it appeals to the child's interest. A welldesigned app can elicit positive emotions and arouse curiosity in the child (Wang et al., 2017). Emotional design research has identified ways in which good design properties can promote positive emotions (Norman, 2004; Plass et al., 2014; Um et al., 2012) in users. These design features (Grevisse et al., 2017) may stimulate positive emotional responses such as pleasure, enjoyment (Tuch et al., 2010), and excitement (Chang et al., 2012) as well increase their interest (Heidig et al., 2015) to continue interacting with the app. Balance, harmony, contrast, and dominance are also design features that can attract attention by creating an aesthetically pleasing object (Jacobs, 2004).

The considerations for the curation of educational apps are summarized in Table 1. 
Table 1. Considerations for the curation of educational apps

\begin{tabular}{ll}
\hline Learning & What learning does the app offer? \\
Learning design & How is the learning designed? \\
Values & What are the ideas promoted? \\
Interactivity & Does it encourage active play rather than passive viewing? \\
Involvement & Does it encourage co-play with others? \\
Motivation & Does it motivate learning? \\
Ease of use & Is it intuitive to use? \\
Appropriateness & Is it (st)age appropriate for the child? \\
Appeal & Is it attractive to the child? \\
\hline
\end{tabular}

\section{APPLYING THE CONSIDERATIONS AND DESCRIPTION OF THE APPS}

In this section, we apply the set of considerations described earlier to demonstrate its usefulness. The educational apps we have chosen are Dr Seuss' The Big Brag, Super Why Alpha Boost!, and Angry Birds. The Big Brag app is highly rated by Common Sense Media purportedly because of its educational value. It provides edutainment value as the story is not only well-acted by the narrator who puts on different voices for the three characters in the story, the rabbit, the bear, and the worm but also provides different types of learning such as vocabulary and socio-emotional learning. In contrast, Super Why Alpha Boost! is lowly rated by Common Sense Media. Moving beyond literacy learning to the learning of physics, we also evaluated the popular app, Angry Birds, which has been highly rated by Common Sense Media as one of the top ten best kids' apps of the decade (2010-2019). It is also the most downloaded freemium game series of all times with more than 3 billion downloads according to Forbes.

The Big Brag ${ }^{1}$ is a picture story app that aims to introduce vocabulary word learning through a narrative to children (ages four plus) using engaging visuals, sounds, and voice acting. Children interact with the story by tapping and swiping to explore the story world and progress the narrative. The app provides the options where children and caregivers can choose whether to allow it to read aloud to them, read it themselves, or auto-play. The story of the app tells us about the rabbit and the bear who boasted that they were the 'best of the beasts' where the rabbit boasted about its hearing abilities and the bear, its smelling ability. Towards the end of the story, they were both humbled by a worm who claimed that it can see all around the world.

Super Why Alpha Boost! ${ }^{2}$ is a party-themed word game app that can be used by children (ages four plus) to learn vocabulary words. Children can choose from one of the four main characters as well as a party theme. After that, they will start to play the game by catching the letters and objects that fall from the top of the screen. After the letters build the words, the game session is completed, and children can choose to move on to the game with the next word.

Angry Birds ${ }^{3}$ is a knock-down-blocks game which the player controls and propels a bird to knock down the pigs that are protected by various structures. The player progresses across the levels. The game is based on the law of Physics and children learn about projectile motion as they play the game. A recent study by de Aldama and Pozo (2020) has reported that, when guided by epistemic goals, students were able to develop conceptions regarding object motion and learn Newtonian physics (parabolic motion).

We first consider the learning that The Big Brag app offers. The app is designed for vocabulary learning through narration of the story and the highlighting of the text simultaneously as the text is narrated. It also teaches children the word-sound correspondence as the children can tap on the individual words to repeat their pronunciations. The app can help children to develop their multimodal semiotic awareness as it integrates multiple modes to communicate meaning to the recipient. For instance, when the rabbit boasted that he was the best, he had a contented expression on his face whereas his expression changed to a look of discontentment when the bear first appeared in the story to challenge his boast verbally.

\footnotetext{
${ }^{1}$ https://tinyurl.com/thebigbrag

2 https://tinyurl.com/alphaboost

${ }^{3}$ https://tinyurl.com/angrybirdapp
} 
The Super Why Alpha Boost! app is designed for vocabulary learning through a game. As children catch the letters, the app will teach them letter-sound correspondence in phonology by pronouncing the letters. As the letters complete a word, the app will also pronounce the word to children to teach them word-sound correspondence in phonology. However, the app does not allow caregivers to guide children to learn the vocabulary words as it only shows the letters and the words but does not provide the visual representation of the words that corresponds to the real-world counterparts of the concept that is being taught. Neither does the app provide for contextualized learning as the letters and words are taught in isolation from other words in a game environment. The child may be more focused on playing the game rather than learning the words and letters because they are attracted to the animations in the game.

In The Big Brag app, learning occurs through practice as the child is prompted to tap on the word again and again for repeated pronunciation until the child can learn how to pronounce the word in the text. There is behaviorist learning as the children are provided with immediate feedback when they tap on the various objects and words in the story world in the form of pronunciation of those objects and words. In Super Why Alpha Boost!, learning takes place through reinforcement as the child will be rewarded with immediate feedback in the form of pronunciation of the letters when they catch the letters. As the child completes the words using the letters, they will also be rewarded with immediate feedback in the pronunciation of the words. However, because there is also other feedback from playing the game that is not relevant to learning the vocabulary words, the child could potentially be distracted from learning the letters and words.

The learning in Angry Birds is designed through trial and error as the player tests out her hypothesis by making several attempts at destroying the pigs. The player learns from each unsuccessful and successful attempt and understands the best way to project the bird to optimize damage. In this, the learning is behaviorist and instant feedback is offered for the player to see the results of her attempt.

In terms of the ideas promoted, The Big Brag app uses anthropomorphized animal characters to convey the main idea that conflict occurs when human beings do not come to a consensus on a topic in a discussion when they choose to focus on their own viewpoints. Incidentally, the message is also conveyed that humility is an important virtue in society and arrogance is not a positive behavior as it contributes to anti-social behavior. There are no overt values being transmitted in the Super Why Alpha Boost! app, apart from the importance of competition, as the learning activities are presented in a decontextualized manner and the learning activities are focused on learning the letters of the alphabets and the words formed from the letters. Like Super Why Alpha Boost!, there are no explicit values communicated in Angry Birds apart from the purported rivalry between animal groups-the birds and the pigs. The app also gamifies the learning process where the players are motivated to move up the levels and surpass their personal high scores.

The Big Brag app encourages active involvement through its interactive features. Children are encouraged to explore the story world by tapping on the different objects, characters, and words in the pages of the picture book app where the app will provide immediate feedback to children by pronouncing the names of these objects. The app also supports co-learning with an adult caregiver who can read the picture story app together with the child, interact with the objects in the story app together with the child, and discuss the conceptual meanings of those objects with the child. However, the app does not motivate continual engagement and learning beyond itself.

Super Why Alpha Boost! also encourages active involvement. Children are encouraged to interact with the app by catching the letters of the alphabet to form words for vocabulary learning. However, the game in the app dominates the engagement and there are no contextual and visual cues that directly guide the child to learn the referent of the words that are being taught. The app does not support co-learning with an adult caregiver as it is playable only in the single mode. The app also cannot be paused to allow the caregiver to discuss with the child about the content. Like The Big Brag, the app does not motivate continual engagement and learning beyond itself.

In terms of active involvement, Angry Birds offers limited interaction beyond the user's control of the bird. There are no other features for the player to explore and co-play with others, including the caregiver is not possible, unless they are competing with each other on separate devices or taking turns on the same device. Given the nature of the competitive gameplay, the opportunity to have the child reflect on the strategy used is limited to when the child loses the game. 
The Big Brag app offers a simple and an intuitive user interface that promotes a positive experience when using it. The user simply needs to tap on the various objects and buttons in the story and immediate feedback will be provided to the user. When the user needs to progress the story, they can simply swipe left using their fingers. If the user wishes to return to the main menu, they can simply tap on a small upward arrow that is found on the bottom left-hand corner of the screen. Super Why Alpha Boost! also offers a simple and intuitive user interface that promotes a positive experience when using the app. The child can simply tap on the various objects and buttons in the game and immediate feedback will be provided to him. When the game is completed, the child can choose another character to learn other letters and words. Like the two apps, Angry Birds has a simple and intuitive user interface. The limited actions which the player can perform to propel the bird also adds to the ease of playing the game.

Both The Big Brag and Super Why Alpha Boost! are arguably developmentally appropriate to a young child who is four years old. The app is simple to use and fulfils its learning purpose of vocabulary learning for the child. The only drawback is that it does not offer differentiated learning by adapting to the child's learning, and does not offer increasingly challenging words for the child to learn. The Super Why Alpha Boost! contains only one game and it does not require any more thinking than just tilting a mobile device back-and-forth. Additionally, once the character on the screen hits specific falling objects, the screen movements speed up at a faster rate such that children playing the game would not be likely to follow the word formation process at the bottom right corner of the screen, making learning less likely. Given the simplicity of the game and the focus on just one aspect of Newtonian physics on projectile motion, Angry Birds is developmentally appropriate for a seven-year-old child which the app has been recommended for. As the child progresses across the levels, the challenge and difficulty increase to offer a differentiated learning experience for more advanced players with every success. The appropriate level of challenge at each level also adds to the draw of the app.

In terms of aesthetics, The Big Brag app does not use warm and bright colors such as red and orange to attract the user. Instead, it uses muted colors such as blue, green, black, and white to reinforce its main message of the value of remaining humble and promoting humility as a virtue. Although the app does not use animation to engage children, it is simple in its layout, symmetrical in the design of its graphics, and is consistent in its style where the words and the graphics occupy their own space in the app's pages and do not intrude into each other.

In contrast, the Super Why Alpha Boost! app is visually attractive as it uses bright and catchy colors together with animations to attract the child to continue playing the game. The layout is symmetrical, and the app uses cartoonish characters to motivate children to play the game in the app. However, the use of bright and catchy colors together with animations and cartoonish characters may cause some children to focus more on playing the game rather than learn the vocabulary words because the learning activities are presented in a decontextualized environment.

Angry Birds is also very visually attractive as it uses primary colors that are bright and highly saturated to attract the players. The use of cartoon characters with different types of birds and pigs serves to enhance its visual appeal especially for children. The music accompanying the gameplay is also catchy and contributes to the overall draw of the app. The global success of Angry Birds could be attributed to the simplicity and elegance in design, ease of play and appropriate level of challenge, as well as the aesthetic appeal in its presentation.

\section{CONCLUSIONS}

In this paper, we have identified a set of considerations that can be used for caregivers in their curation of educational apps. Given that many caregivers are busy and are not familiar with educational theories and pedagogical ideas, as education researchers, our goal in this study is to translate the findings from literature into a set of practical resource in accessible language for caregivers.

The considerations identified are informed from a review of past studies and can guide the caregivers to pay attention to aspects of the apps which might be neglected in a cursory review. In particular, the considerations invite the caregivers to reflect on the value of the app in relation to the learning it offers as well as the way in which the learning is designed. It also encourages the caregiver to be mindful of the values which could be both intentionally and incidentally promoted through the use of the app. Building on the 
research of the value of active play, the considerations also include the extent of interactivity and involvement with other which the app can offer to the child. In addition, the extent in which the app can motivate the child to learn beyond itself is also a useful consideration as the app can then serve as a springboard to further learning. Finally, considerations such as the ease of use, appeal as well as age and stage appropriateness for the child are explicated so that the curated app will be of interest and can be easily used by the child.

While this set of considerations may not be exhaustive, we hope that they will serve as a conversation starter for educational researchers interested in extending this work on digital play, and as a resource for caregivers, both parents and early childhood educators included. This set of considerations has been incorporated in the development of a caregiver's digital play resource kit, which includes ideas of activities that caregivers can use when using various educational apps with their children as well as strategies for productive digital co-play 4 . Beyond our primary goal of supporting caregivers, we also posit that such a set of considerations can inform educational app developers to be more mindful of the pedagogical and design aspects in which they need to address in the making of a useful educational app.

Admittedly, the considerations are broad and rely on the judgements of caregivers when curating educational apps for use with children. However, this is intended as we recognise that caregivers may have different parenting styles as well as a range of interests and priorities. As such, the considerations are not designed to be prescriptive. Rather, they are meant to support caregivers by offering considerations to guide them in their decision-making. Rather than relying on the reviews by others, we argue that explicating a set of research-informed considerations for the curation of educational apps can be empowering to caregivers in guiding their children in digital play for learning.

Author contributions: All authors were involved in concept, design, collection of data, interpretation, writing, and critically revising the article. All authors approve final version of the article.

Funding: This study was funded by the Start Up Grant for New Assistant Professors (SUG-NAP) at the National Institute of Education, Nanyang Technological University, Singapore.

Declaration of interest: Authors declare no competing interest.

Data availability: Data generated or analyzed during this study are available from the authors on request.

\section{REFERENCES}

Arnold, D. H., Chary, M., Gair, S. L., Helm, A. F., Herman, R., Kang, S., \& Lokhandwala, S. (2021). A randomized controlled trial of an educational app to improve preschoolers' emergent literacy skills. Journal of Children and Media, 15(4), 457-475. https://doi.org/10.1080/17482798.2020.1863239

Ausubel, D. (1968). Educational psychology: A cognitive view. Rinehart \& Winston.

Barnes, E. M. (2013). Head start preschool teachers' commenting practices during shared book reading sessions: describing learning opportunities for children with varying vocabulary abilities [Doctoral dissertation, Vanderbilt University].

Barnes, E. M., Dickinson, D. K., \& Grifenhagen, J. F. (2016). The role of teachers' comments during book reading in children's vocabulary growth. The Journal of Educational Research, 110(5), 515-527. https://doi.org/10.1080/00220671.2015.1134422

Blewitt, P., Rump, K. M., Shealy, S. E., \& Cook, S. A. (2009). Shared book reading: When and how questions affect young children's word learning. Journal of Educational Psychology, 101(2), 294-304. https://doi.apa.org/doi/10.1037/a0013844

Brown, H. (1994). Principles of language learning and teaching. Prentice Hall.

Brown, P. C., Roediger, H. L., \& McDaniel, M. A. (2014). Make it stick: The science of successful learning. Harvard University Press. https://doi.org/10.4159/9780674419377

Bus, A. G., Takacs, Z. K., \& Kegel, C. A. T. (2015). Affordances and limitations of electronic storybooks for young children's emergent literacy. Developmental Review, 35, 79-97. https://doi.org/10.1016/j.dr.2014.12.004

Callaghan, M. N., \& Reich, S. M. (2018). Are educational preschool apps designed to teach? An analysis of the app market. Learning, Media, and Technology, 43(3), 280-293. https://doi.org/10.1080/17439884.2018. 1498355

CASEL. (2019). What is SEL? https://casel.org/what-is-sel/

${ }^{4}$ https://eduappsresearch.wixsite.com/website/starter-kit 
Cassady, J. C., \& Smith, L. L. (2005). The impact of a structured integrated learning system on first-grade students' reading gains. Reading \& Writing Quarterly, 21(4), 361-376. https://doi.org/10.1080/ 10573560591002277

Chang, T.-R., Kaasinen, E., \& Kaipainen, K. (2012). What influences users' decisions to take apps into use?: A framework for evaluating persuasive and engaging design in mobile Apps for well-being. In Proceedings of the 11th International Conference on Mobile and Ubiquitous Multimedia (pp. 1-10). https://doi.org/10.1145/2406367.2406370

Chew, E. C., \& Mitchell, A. (2019). Bringing art to life: Examining poetic gameplay devices in interactive life stories. Games \& Culture, 15(8), 874-901. https://doi.org/10.1177/1555412019853372

de Aguiar, M. P., Winn, B., Cezarotto, M., Battaiola, A. L., \& Varella, G. P. (2018). Educational digital games: A theoretical framework about design models, learning theories and user experience. In A. Marcus \& W. Wang (Eds.), Design, user experience, and usability: Theory and practice (pp. 165-184). Springer, Cham. https://doi.org/10.1007/978-3-319-91797-9_13

de Aldama, C., \& Pozo, J.-I. (2020). Do you want to learn physics? Please play angry birds (but with epistemic goals). Journal of Educational Computing Research, 58(1), 3-28. https://doi.org/10.1177/ 0735633118823160

Department for Education. (2019). Educational criteria for early years app. https://assets.publishing.service.gov. uk/government/uploads/system/uploads/attachment_data/file/822086/Educational_criteria.pdf

Deterding, S., Dixon, D., Khaled, R., \& Nacke, L. (2011). From game design elements to gamefulness: Defining "gamification". In Proceedings of the 15th International Academic MindTrek Conference: Envisioning Future Media Environments (pp. 9-15). Tampere, Finland. https://doi.org/10.1145/2181037.2181040

Dichev, C., \& Dicheva, D. (2017). Gamifying education: What is known, what is believed and what remains uncertain: A critical review. International Journal of Educational Technology in Higher Education, $14,9$. https://doi.org/10.1186/s41239-017-0042-5

Dickinson, D. K., Hirsh-Pasek, K., Golinkoff, R. M., Nicolopoulou, A., \& Collins, M. F. (2013). The read-play-learn intervention and research design [Paper presentation]. Biennial Meeting of the Society for Research in Child Development in Seattle, WA, USA.

Djonov, E., Tseng, C.-I., \& Lim, F. V. (2021). Children's experiences with a transmedia narrative: Insights for promoting critical multimodal literacy in the digital age. Discourse, Context \& Media, 43, 100493.

Dore, R. A., Shirilla, M., Hopkins, E., Collins, M., Scott, M., Schatz, J., Lawson-Adams, J., Valladares, T., Foster, L., Puttre, H., Toub, T. S., Hadley, E., Golinkoff, R. M., Dickinson, D., \& Hirsh-Pasek, K. (2019). Education in the app store: Using a mobile game to support U.S. preschoolers' vocabulary learning. Journal of Children and Media, 13(4), 452-471. https://doi.org/10.1080/17482798.2019.1650788

Dubé, A. K., Kacmaz, G., Wen, R., Alam, S. Z., \& Xu, C. (2020). Identifying quality educational apps: Lessons from 'top' mathematics apps in the Apple App store. Education and Information Technologies, 25, 5389-5404. https://doi.org/10.1007/s10639-020-10234-z

Eyal, N., \& Hoover, R. (2014). Hooked: How to build habit-forming products. Sunshine Business Development.

Gibbs, R. W. (2003). Embodied experience and linguistic meaning. Brain and Language, 84(1), 1-15. https://doi.org/10.1016/S0093-934X(02)00517-5

Gibbs, R. W. (2005). Embodiment and cognitive science. Cambridge University Press. https://doi.org/10.1017/ CBO9780511805844

Grevisse, C., Botev, J., \& Rothkugel, S. (2017). Yactul: An extensible game-based student response framework for active learning. In XVIII Encuentro Internacional Virtual Educa Colombia 2017 [XVIII International Meeting Virtual Education Colombia 2017]. Columbia.

Griffith, S. F., Hagan, M. B., Heymann, P., Heflin, B. H., \& Bagner, D. M. (2020). Apps as learning tools: A systematic review. Pediatrics, 145(1), 1-14. https://doi.org/10.1542/peds.2019-1579

Griffith, S. F., Hanson, K. G., Rolon-Arroyo, B., \& Arnold, D. H. (2019). Promoting early achievement in lowincome preschoolers in the United States with educational apps. Journal of Children and Media, 13(3), 328-344. https://doi.org/10.1080/17482798.2019.1613246

Hadley, E. B., Dickinson, D. K., Hirsh-Pasek, K., \& Golinkoff, R. M. (2018). Building semantic networks: The impact of a vocabulary intervention on preschoolers' depth of word knowledge. Reading Research Quarterly, 54(1), 41-61. https://doi.org/10.1002/rrq.225 
Hatzigianni, M., Gregoriadis, A., Karagiorgou, I., \& Chatzigeorgiadou, S. (2018). Using tablets in free play: The implementation of the digital play framework in Greece. British Journal of Educational Technology, 49(5), 928-942. https://doi.org/10.1111/bjet.12620

Heidig, S., Müller, J., \& Reichelt, M. (2015). Emotional design in multimedia learning: Differentiation on relevant design features and their effects on emotions and learning. Computers in Human Behavior, 44, 81-95. https://doi.org/10.1016/j.chb.2014.11.009

Hindman, A. H., Skibbe, L. E., \& Foster, T. D. (2014). Exploring the variety of parental talk during shared book reading and its contributions to preschool language and literacy: Evidence from the early childhood longitudinal study-birth cohort. Reading \& Writing, 27(2), 287-313. https://doi.org/10.1007/s11145-0139445-4

Hirsh-Pasek, K., Zosh, J. M., Michnick, G., Gray, J. H., Robb, M. B., \& Kaufman, J. (2015). Putting education in "educational" apps: Lessons from the science of learning. Psychological Science in the Public Interest, 16(1), 3-34. https://doi.org/10.1177/1529100615569721

Jacobs, M. (2004). Graphic design concepts. Words \& Pictures Publishing.

Juan, C., Beatrice, F., \& Cano, J. (2008). An augmented reality system for learning the interior of the human body. In Eighth IEEE International Conference on Advanced Learning Technologies. https://doi.org/10.1109/ ICALT.2008.121

Kezar, A., \& Rhoads, R. A. (2001). The dynamic tensions of service learning in higher education: A philosophical perspective. Higher Education, 72(2), 148-171. https://doi.org/10.1080/00221546.2001.11778876

Kiger, M. E., \& Varpio, L. (2020). Thematic analysis of qualitative data: AMEE guide No. 131. Medical Teacher, 42(8), 846-854. https://doi.org/10.1080/0142159X.2020.1755030

Kim, J. S., Capotosto, L., Hartry, A., \& Fitzgerald, R. (2011). Can a mixed-method literacy intervention improve the reading achievement of low-performing elementary school students in an after-school program?: Results from a randomized controlled trial of READ 180 enterprise. Educational Evaluation \& Policy Analysis, 33(2), 183-201. https://doi.org/10.3102/0162373711399148

Kolak, J., Norgate, S. H., Monaghan, P., \& Taylor, G. (2021). Developing evaluation tools for assessing the educational potential of apps for preschool children in the UK. Journal of Children and Media, 15(3), 410430. https://doi.org/10.1080/17482798.2020.1844776

Kress, G., \& Jewitt, C. (2003). Introduction. In C. Jewitt, \& G. Kress (Eds.), Multimodal literacy (pp. 1-18). Peter Lang.

Kucirkova, N. (2019). Children's agency by design: Design parameters for personalization in story-making apps. International Journal of Child-Computer Interaction, 21, 112-120. https://doi.org/10.1016/j.ijcci.2019. 06.003

Kucirkova, N., \& Sakr, M. (2015). Child-father creative text-making at home with crayons, iPad collage \& PC. Thinking Skills and Creativity, 17, 59-73. https://doi.org/10.1016/j.tsc.2015.05.003

Kuh, G. D. (1996). Guiding principles for creating seamless learning environments for undergraduates. Journal of College Student Development, 37(2), 135-148.

Lee, C.-Y., \& Sloan Cherner, T. (2015). A comprehensive evaluation rubric for assessing instructional apps. Journal of Information Technology Education: Research, 14, 021-053. https://doi.org/10.28945/2097

Lee, J.-S., \& Kim, S.-W. (2015). Validation of a tool evaluating educational apps for smart education. Journal of Educational Computing Research, 52(3), 435-450. https://doi.org/10.1177/0735633115571923

Lim, F. V. (2018). Developing a systemic functional approach to teach multimodal literacy. Functional Linguistics, 5, 13. https://doi.org/10.1186/s40554-018-0066-8

Lim, F. V. (2021). Designing learning with embodied teaching. Perspectives from multimodality. Routledge.

Lim, F. V., \& Tan, K.Y.S. (2017). Multimodal translational research: Teaching visual texts. In O. Seizov \& J. Wildfeuer (Eds.), New studies in multimodality: Conceptual and methodological elaborations (pp. 175-199). Bloomsbury. https://doi.org/10.5040/9781350026544.0014

Lim, F. V., \& Toh, W. (2020). Children's digital multimodal composing: Implications for learning and teaching. Learning, Media and Technology, 45(4), 422-432. https://doi.org/10.1080/17439884.2020.1823410

Lim, F. V., Cope, B., \& Kalantzis, M. (2022). A metalanguage for learning: Rebalancing the cognitive with the socio-material. Frontiers in Communication, 7, 830613. https://doi.org/10.3389/fcomm.2022.830613 
Lim, F. V., Woo, H. M., \& Lee, M. Y. (2016). Serious games to develop social and emotional learning in students. In T. Marsh, M. Ma, M. Oliveira, J. Baalsrud Hauge, \& S. Göbel (Eds.), Lecture notes in computer science (Vol. 9894). Springer. https://doi.org/10.1007/978-3-319-45841-0_1

Lin, B., Sarah-Jane, L., \& Andrei, C. (2017). Gender stereotypes about intellectual ability emerge early and influence children's interests. Science, 355(6323), 389-391. https://doi.org/10.1126/science.aah6524

Liu, T.-Y., Tan, T.-H., \& Chu, Y.-L. (2009). Outdoor natural science learning with an RFID-supported immersive ubiquitous learning environment. Journal of Educational Technology \& Society, 12(4), 161-175.

Lochmiller, C. R. (2021). Conducting thematic analysis with qualitative data. Qualitative Report, 26(6), 20292044. https://doi.org/10.46743/2160-3715/2021.5008

Malone, T. W., \& Lepper, M. R. (1987). Making learning fun: A taxonomy of intrinsic motivations for learning. In R. E. Snow, \& M. J. Farr (Eds.), Aptitude, learning, and instruction: III. Conative and affective process analyses (pp. 223-253). Erlbaum.

Mekler, E. D., Brühlmann, F., Tuch, A. N., \& Opwis, K. (2017). Towards understanding the effects of individual gamification elements on intrinsic motivation and performance. Computers in Human Behavior, 71, 525534. https://doi.org/10.1016/j.chb.2015.08.048

Morrison, A., Oulasvirta, A., Peltonen, P., Lemmela, S., Jacucci, G., Reitmayr, G., Nasanen, J., \& Juustila, A. (2009). Like bees around the hive: A comparative study of a mobile augmented reality map. In Proceedings of the SIGCHI Conference on Human Factors in Computing Systems (pp. 1889-1898). https://doi.org/10.1145/ 1518701.1518991

Nicolopoulou, A., Toub, T. S., Hassinger-Das, B., Nesbitt, K. T., Ilgaz, H., Dickinson, D. K., Weisberg, D. S., HirshPasek, K., \& Golinkoff, R. M. (2018). The language of play: Developing preschool vocabulary through play following shared book-reading. Early Childhood Research Quarterly, 45, 1-17. https://doi.org/10.1016/ j.ecresq.2018.01.010

Nightingale, D., \& Cromby, J. (1999). Social constructionist psychology: A critical analysis of theory and practice. McGraw-Hill Education.

Noorhidawati, A., Ghalebandi, S. G., \& Hajar, R. S. (2015). How do young children engage with mobile apps? Cognitive, psychomotor, and affective perspective. Computers \& Education, 87, 385-395. https://doi.org/10.1016/j.compedu.2015.07.005

Norman, D. A. (2004). Emotional design: Why we love (or hate) everyday things. Basic Books.

Nowell, L. S., Norris, J. M., White, D. E., \& Moules, N. J. (2017). Thematic analysis: Striving to meet the trustworthiness criteria. International Journal of Qualitative Methods, 16(1), 1-13. https://doi.org/10.1177/1609406917733847

Papadakis, S., \& Kalogiannakis, M. (2017). Mobile educational applications for children: What educators and parents need to know. International Journal of Mobile Learning and Organisation, 11(3), 256-277. https://doi.org/10.1504/IJMLO.2017.085338

Papadakis, S., Kalogiannakis, M., \& Zaranis, N. (2018). Educational apps from the android Google Play for Greek preschoolers: A systematic review. Computers \& Education, 116, 139-160. https://doi.org/10.1016/ j.compedu.2017.09.007

Papert, S. (1995). The parent trap. Time Magazine. http://www.papert.org/articles/parent_trap.html

Parish-Morris, J., Mahajan, N., Hirsh-Pasek, K., Golinkoff, R. M., \& Collins, M. F. (2013). Once upon a time: Parent-child dialogue and storybook reading in the electronic era. Mind, Brain, and Education, 7(3), 200211. https://doi.org/10.1111/mbe.12028

Pelton, T., \& Pelton, F. (2011). Design principles for making meaningful mathematics apps [Paper presentation]. Society for Information Technology \& Teacher Education International Conference.

Perez-Lopez, D., \& Contero, M. (2013). Delivering educational multimedia contents through an augmented reality application: A case study on its impact on knowledge acquisition and retention. Turkish Online Journal of Educational Technology, 12(4), 19-28.

Piotrowski, J. T., \& Krcmar, M. (2017). Reading with hotspots: Young children's responses to touchscreen stories. Computers in Human Behavior, 70, 328-334. https://psycnet.apa.org/doi/10.1016/j.chb.2017.01. 010

Plass, J. L., Heidig, S., Hayward, E. O., Homer, B. D., \& Um, E. (2014). Emotional design in multimedia learning: Effects of shape and color on affect and learning. Learning and Instruction, 29, 128-140. https://doi.org/10.1016/j.learninstruc.2013.02.006 
Ponce, H. R., López, M. J., \& Mayer, R. E. (2012). Instructional effectiveness of a computer-supported program for teaching reading comprehension strategies. Computers \& Education, 59(4), 1170-1183. https://doi.org/10.1016/j.compedu.2012.05.013

Pressley, M., \& Levin, J. R. (1985). Keywords and vocabulary acquisition: Some words of caution about Johnson, Adams, and Bruning. Educational Communication and Technology, 33(4), 277-284. https://doi.org/10.1007/BF02769365

Reese, E., \& Cox, A. (1999). Quality of adult book reading affects children's emergent literacy. Developmental Psychology, 35(1), 20-28. https://doi.apa.org/doi/10.1037/0012-1649.35.1.20

Schneider, D., Chambers, A., Mather, N., Bauschatz, R., Bauer, M., \& Doan, L. (2016). The effects of an ICTbased reading intervention on students' achievement in grade two. Reading Psychology, 37(5), $793-831$. https://doi.org/10.1080/02702711.2015.1111963

Selander, S., Lim, F.V., Wiklund, M., \& Fors, U. (2018). Digital games and simulations for learning. In H. C. Arnseth, T. Hanghoj, T. D. Henriksen, M. Misfeldt, S. Selander, \& R. Ramberg (Eds.), Games and education: Designs in and for learning (pp. 17-27). Sense Publishers.

Shoukry, L., Sturm, C., \& Galal-Edeen, G. H. (2015). Pre-MEGa: A proposed framework for the design and evaluation of preschoolers' mobile educational games. In T. Sobh, \& K. Elleithy (Eds.), Innovations and advances in computing, informatics, systems sciences, networking and engineering (pp. 385-390). Springer, Cham. https://doi.org/10.1007/978-3-319-06773-5_52

Smith, P. L., \& Ragan, T. J. (2005). Instructional design. Merill.

Squires, D., \& Preece, J. (1999). Predicting quality in educational software: Evaluating for learning, usability and the synergy between them. Interacting with Computers, 11(5), 467-483. https://doi.org/10.1016/S09535438(98)00063-0

Sung, H.-Y., \& Chen, S.-H. (2018). "The screen shows movement-movement is interesting!" exploring effects of multimedia stories on preschool children's story comprehension and enjoyment. Library Hi Tech, 37(2), 168-182. https://doi.org/10.1108/LHT-04-2018-0057

Takacs, Z. K., Swart, E. K., \& Bus, A. G. (2015). Benefits and pitfalls of multimedia and interactive features in technology-enhanced storybooks: A meta-analysis. Review of Educational Research, 85(4), 698-739. https://doi.org/10.3102/0034654314566989

Tarasuik, J., Demaria, A., \& Kaufman, J. (2017). Transfer of problem solving skills from touchscreen to 3D model by 3- to 6-year-olds. Frontiers in Psychology, 8, 1-6. https://doi.org/10.3389/fpsyg.2017.01586

Toh, W. (2021). The economics of decision-making in video games. Game Studies, 21(3). http://gamestudies.org/2103/articles/toh

Toh, W., \& Kirschner, D. (2020). Self-directed learning in video games, affordances and pedagogical implications for teaching and learning. Computers \& Education, 154, 1-11. https://doi.org/10.1016/j.compedu.2020.103912

Toh, W., \& Lim, F. V. (2021a). Let's play together: Ways of parent-child digital co-play for learning. Interactive Learning Environments. Advance online publication. https://doi.org/10.1080/10494820.2021.1951768

Toh, W., \& Lim, F. V. (2021b). Using video games for learning: Developing a metalanguage for digital play. Games and Culture, 16(5), 583-610. https://doi.org/10.1177/1555412020921339

Toh, W., \& Lim, F. V. (2022). Learning in digital play: A dual case study of video gamers' independent play. Research and Practice in Technology Enhanced Learning, 17, 6. https://doi.org/10.1186/s41039-022-001822

Towndrow, P. A., Nelson, M. E., \& Yusuf, W. F. B. M. (2013). Squaring literacies assessment with multimodal design: An analytic case for semiotic awareness. Journal of Literacy Research, 45(4), 327-355. https://doi.org/10.1177/1086296X13504155

Tuch, A. N., Bargas-Avila, J. A., \& Opwis, K. (2010). Symmetry and aesthetics in website design: It's a man's business. Computers in Human Behavior, 26(6), 1831-1837. https://doi.org/10.1016/j.chb.2010.07.016

Tuckett, A. G. (2005). Applying thematic analysis theory to practice: A researcher's experience. Contemporary Nurse, 19(1-2), 75-87. https://doi.org/10.5172/conu.19.1-2.75

Um, E., Plass, J. L., Hayward, E. O., \& Homer, B. D. (2012). Emotional design in multimedia learning. Journal of Educational Psychology, 104(2), 485-498. https://doi.org/10.1016/j.chb.2014.11.009

van Leeuwen, T. (2017). Multimodal literacy. Viden om laesning [Knowledge about reading], 21, 4-11. 
Vungthong, S., Djonov, E., \& Torr, J. (2015). Images as a resource for supporting vocabulary learning: A multimodal analysis of Thai EFL tablet apps for primary school children. TESOL Quarterly, 51(1), 32-58. https://doi.org/10.1002/tesq.274

Wang, Y., Chen, J., \& Yue, Z. (2017). Positive emotion facilitates cognitive flexibility: An fMRI study. Frontiers in Psychology, 8, 1-11. https://doi.org/10.3389/fpsyg.2017.01832

Wise, D., \& Jacobo, A. (2010). Towards a framework for leadership coaching. School Leadership \& Management, 30(2), 159-169. https://doi.org/10.1080/13632431003663206

Withey, K. L. (2016). Using apps to develop social skills in children with autism spectrum disorder. Intervention in School and Clinic, 52(4), 250-255. https://doi.org/10.1177/1053451216659475

Xu, W., \& Zammit, K. (2020). Applying thematic analysis to education: A hybrid approach to interpreting data in practitioner research. International Journal of Qualitative Methods, 19, 1-9. https://doi.org/10.1177/1609406920918810

Zhao, S., \& Unsworth, L. (2017). Touch design and narrative interpretation: A social semiotic approach to picture book apps. In K. Natalia, \& G. Falloon (Eds.), Apps, technology and younger learners: International evidence for teaching (pp. 87-98). Routledge. 